\title{
KSHV-encoded miRNAs target MAF to induce endothelial cell reprogramming
}

\author{
Amy Hansen, ${ }^{1}$ Stephen Henderson, ${ }^{1,6}$ Dimitrios Lagos, ${ }^{1,6}$ Leonid Nikitenko, ${ }^{1}$ Eve Coulter, ${ }^{2}$ \\ Sinead Roberts, ${ }^{1}$ Fiona Gratrix,${ }^{1}$ Karlie Plaisance, ${ }^{3}$ Rolf Renne, ${ }^{3}$ Mark Bower, ${ }^{4}$ Paul Kellam, \\ and Chris Boshoff ${ }^{1,7}$ \\ ${ }^{1}$ Cancer Research UK Viral Oncology Group, University College London Cancer Institute, University College London, London \\ WC1E 6BT, United Kingdom; ${ }^{2}$ Division of Infection and Immunity, University College London, London W1T 4JF, United \\ Kingdom; ${ }^{3}$ Department of Molecular Genetics and Microbiology, University of Florida College of Medicine, Gainesville, Florida \\ 32610, USA; ${ }^{4}$ Imperial College London, London SW7 2AZ, United Kingdom; ${ }^{5}$ Wellcome Trust Sanger Institute, Hinxton, \\ Cambridge CB10 1SA, United Kingdom
}

Kaposi sarcoma herpesvirus (KSHV) induces transcriptional reprogramming of endothelial cells. In particular, KSHV-infected lymphatic endothelial cells (LECs) show an up-regulation of genes associated with blood vessel endothelial cells (BECs). Consequently, KSHV-infected tumor cells in Kaposi sarcoma are poorly differentiated endothelial cells, expressing markers of both LECs and BECs. MicroRNAs (miRNAs) are short noncoding RNA molecules that act post-transcriptionally to negatively regulate gene expression. Here we validate expression of the KSHV-encoded miRNAs in Kaposi sarcoma lesions and demonstrate that these miRNAs contribute to viralinduced reprogramming by silencing the cellular transcription factor MAF (musculoaponeurotic fibrosarcoma oncogene homolog). MAF is expressed in LECs but not in BECs. We identify a novel role for MAF as a transcriptional repressor, preventing expression of BEC-specific genes, thereby maintaining the differentiation status of LECs. These findings demonstrate that viral miRNAs could influence the differentiation status of infected cells, and thereby contribute to KSHV-induced oncogenesis.

[Keywords: MAF; viral miRNAs; Kaposi; lymphatic endothelium]

Supplemental material is available at http://www.genesdev.org.

Received August 18, 2009; revised version accepted November 23, 2009.

Kaposi sarcoma (KS) is the most frequent tumor in untreated HIV-infected individuals (Boshoff and Weiss 2002). KS is a highly vascularized tumor comprised of poorly differentiated spindle-shaped endothelial cells and characterized by a significant inflammatory infiltrate. Disease progression is driven by the proliferation of spindle cells, and they are the predominant cell type in advanced lesions (Boshoff et al. 1995). Spindle cells are latently infected with KS herpesvirus (KSHV, or human herpesvirus-8), the etiological agent of KS (Chang et al. 1994; Boshoff et al. 1995; Staskus et al. 1997).

The overall gene expression profile of KS is closer to that of lymphatic endothelial cells (LECs), than to that of blood vessel endothelial cells (BECs) (Wang et al. 2004). However, KS spindle cells are poorly differentiated and do not faithfully represent either cell lineage, expressing markers of both BECs (e.g., CXCR4 and CD34) (Regezi et al. 1993) and LECs (e.g., VEGFR-3 and LYVE-1) (Dupin

\footnotetext{
${ }^{6}$ These authors contributed equally to this work.

${ }^{7}$ Corresponding author.

E-MAIL c.boshoff@ucl.ac.uk; FAX 44-20-7679-6817.

Article is online at http://www.genesdev.org/cgi/doi/10.1101/gad.553410.
}

et al. 1999; Weninger et al. 1999; Kahn et al. 2002). BECs and LECs are two closely related endothelial cell types that form the vessel walls of blood and lymphatic vasculature, respectively. Lymphatic identity is initiated by expression of the homeodomain transcription factor PROX1 (prospero-related homeobox 1) in a subset of venous endothelial cells early during embryogenesis (Wigle and Oliver 1999|. PROX1 expression is required for both the initiation and maintenance of the LEC phenotype, and PROX1 down-regulation in adult mice leads to lymphatic vasculature defects, loss of expression of LEC markers, and acquisition of ectopic markers characteristic of BECs (Johnson et al. 2008). Therefore, LEC identity appears plastic, with the default state being that of BECs (Bixel and Adams 2008).

$\mathrm{KSHV}$ is capable of reprogramming endothelial cell transcriptomes: In vitro, KSHV infection of BECs induces lymphatic markers, including PROX1 (Hong et al. 2004), whereas KSHV infection of LECs induces transcriptional reprogramming toward a more BEC-like phenotype (Carroll et al. 2004; Hong et al. 2004; Wang et al. 2004). However, the molecular mechanism underlying these transcriptional changes is unknown. 
KSHV encodes 17 mature microRNAs (miRNAs) (Cai et al. 2005; Pfeffer et al. 2005; Samols et al. 2005), 14 of which are coexpressed as a cluster. The KSHV miRNAs are latently transcribed, and expression of a subset of viral pre-miRNAs has been confirmed in KS $\left(\mathrm{O}^{\prime}\right.$ Hara et al. 2009). The function of the KSHV miRNAs is poorly characterized. Confirmed cellular targets include thrombospondin (Samols et al. 2007), BACH1 (Gottwein et al. 2007; Skalsky et al. 2007), and BCLAF1 (Ziegelbauer et al. 2009). However, no LEC-specific KSHV miRNA targets have been identified.

Mammalian miRNAs are involved in mediating cellular differentiation and reprogramming (Chen et al. 2004; Thum et al. 2007; Viswanathan et al. 2008). To date, all validated viral miRNA targets are involved in regulating viral reactivation, apoptosis, or modulating immune responses (Umbach and Cullen 2009). We postulated that viral miRNAs may also affect cellular differentiation, and that KSHV-encoded miRNAs could play a role in mediating the transcriptional reprogramming of endothelial cells. Using gene expression microarray analysis, we identified potential KSHV miRNA targets in LECs, including the leucine zipper transcription factor MAF (musculoaponeurotic fibrosarcoma oncogene homolog). MAF plays a role in tissue specification and terminal differentiation of a wide variety of cell types (Eychene et al. 2008), and here we investigated whether it also played a role in the differentiation status of LECs.

\section{Results}

\section{KSHV miRNA expression in KS}

In order to determine which of the KSHV miRNAs were expressed and therefore biologically relevant to KS pathogenesis, we performed Agilent miRNA profiling of AIDSKS lesions.

The focus of this study was to determine the expression profile of the viral miRNAs; we therefore used KSHVnegative skin biopsies as a negative control, allowing a baseline to be set for miRNA detection in samples lacking viral miRNA expression. KSHV viral gene expression was confirmed in all KS lesions by quantitative RT-PCR (qRTPCR) for the latency-associated nuclear antigen (LANA) (Supplemental Fig. 1A). No viral gene expression was detected in the skin biopsies (Supplemental Fig. 1A).

Expression levels of individual KSHV miRNAs in KS biopsies and normal skin are shown in Figure 1A. Only those miRNAs with significant differential expression between skin and KS are shown. Ten out of the 17 mature viral miRNAs had significantly higher expression in KS than noninfected skin (Fig. 1A). miR-K12-4, miR-K12-1, miRK12-11, and miR-K12-6-5p show the most significant differential expression. For the remaining seven KSHV mature miRNAs, either no expression was detected or probes for these miRNAs cross-reacted in both KSHV-positive and KSHV-negative samples (Supplemental Fig. 1B).

In order to confirm the viral miRNA microarray data, we performed qRT-PCR quantification of the mature form of all KSHV miRNAs (Fig. 1B; Supplemental Fig.
A

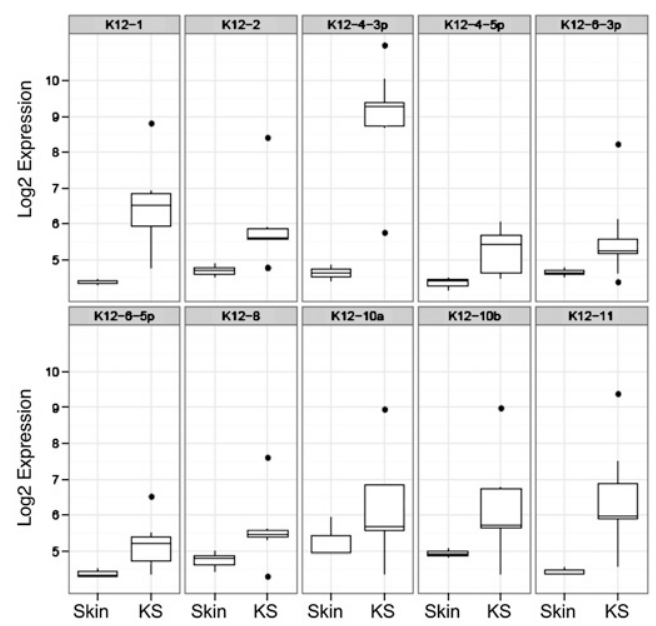

B

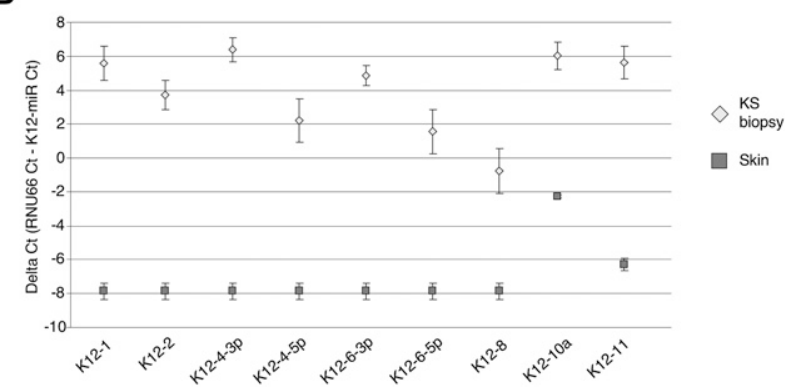

Figure 1. KSHV miRNA expression in KS. $(A)$ Microarray $\log 2$ expression value of significantly expressed miRNA in KS biopsies (relative to KSHV-negative skin, $P<0.05$ ). Box plots show the median, interquartile boxes, 95th percentile range, and outliers as points. Five AIDS-KS biopsies and three KSHV-negative reference skin samples were profiled. (B) qRT-PCR confirmation of the miRNA profiling data. All miRNAs assayed were expressed at higher levels in KS lesions compared with normal skin. Values were normalized to RNU66. The $\Delta$ Ct represents the difference in threshold detection cycle between RNU66 and viral miRNA. Viral miRNAs were undetectable in skin biopsies.

1C). The difference in threshold detection cycle $(\Delta \mathrm{Ct})$ between each KSHV miRNA and RNU66 is shown in both KS lesions and skin. Viral miRNAs with a $\Delta \mathrm{Ct}$ of $>0$ are detected earlier and therefore are more abundant than the small nucleolar RNA RNU66. The majority of KSHV miRNAs were undetectable after 40 cycles of amplification in normal skin samples, generating a $\Delta \mathrm{Ct}$ of -8 (Fig. 1B; Supplemental Fig. 1C).

The qRT-PCR data confirm expression of the nine miRNAs identified by the miRNA microarray (Fig. 1A,B). In addition, miR-K12-5 and miRK-12-12 were detected in KS lesions by qRT-PCR (Supplemental Fig. 1C). This discrepancy may be due to a higher detection threshold of qRT-PCR or might be a consequence of miRNA microarray probe design. A naturally occurring polymorphism exists in the precursor stem-loop of miR-K12-5 that inhibits Drosha processing, leading to diminished mature miRNA levels (Gottwein et al. 2006). It is possible that KS biopsies were infected with a viral strain possessing 
this polymorphism, and that miR-K12-5 is present at low levels. Similar to the miRNA microarray, miR-K12-7 amplified in both KS and KSHV-negative skin samples; therefore, we were unable to confirm its expression in KS lesions (Supplemental Fig. 1C). However, we detected significant differential expression of miR-K12-3 between KS and skin samples, suggesting this miRNA may be expressed (Supplemental Fig. 1C). miR-K12-3*, miR-K12-9, and miR-K12-9* had low $\Delta$ Cts in both skin and KS (Supplemental Fig. 1C).

\section{MAF is a target for KSHV-encoded miRNAs}

miRNA targets are cell-type-specific. Therefore, in order to identify KSHV miRNA targets in LECs, we subcloned the genomic region encoding the KSHV miRNA cluster (Fig. 2A; Samols et al. 2007) into lentiviral vector pSINMCS (Vart et al. 2007). Expression of the mature miRNAs from the lentiviral vector was confirmed by qRT-PCR in LECs transduced with the cluster (Supplemental Fig. 2A).

The majority of mature viral miRNAs were expressed from the lentiviral vector. qRT-PCR of two miRNASmiR-K12-10a and miR-K12-12-not present in the clus- ter generated a $\Delta \mathrm{Ct}$ of less than -4.8 . miRNAs K12-3* and $\mathrm{K} 12-9^{\star}$ also had $\Delta$ Cts of less than -4.8 , suggesting that these miRNAs are not expressed. Expression of miR-K12-6-5p and miR-K12-11 was also confirmed in LECs transduced with individual KSHV miRNAs (Supplemental Fig. 2B). Activity of KSHV cluster miRNAs was confirmed in 293T cells using sensor vectors possessing synthetic KSHV miRNA target sites inserted downstream from the firefly luciferase coding sequence (Supplemental Fig. 2C; Samols et al. 2007).

To identify cellular mRNAs targeted by the KSHV miRNAs, we compared the gene expression profile of LECs transduced with a KSHV miRNA cluster to that of an empty lentiviral vector (Fig. 2B; Supplemental Table 1). Regulation of mRNA transcripts by miRNAs is mediated predominantly through binding sites located in the $3^{\prime}$ untranslated region (UTR) (Gu et al. 2009). Using the target prediction program PITA (Kertesz et al. 2007), we scanned the 3'UTRs of all genes showing decreased expression in the presence of the cluster for potential KSHV miRNA-binding sites. For each down-regulated transcript, the cumulative PITA score for all expressed viral miRNAs (Fig. 1A,B) was calculated (Fig. 2B, negative ddG
A

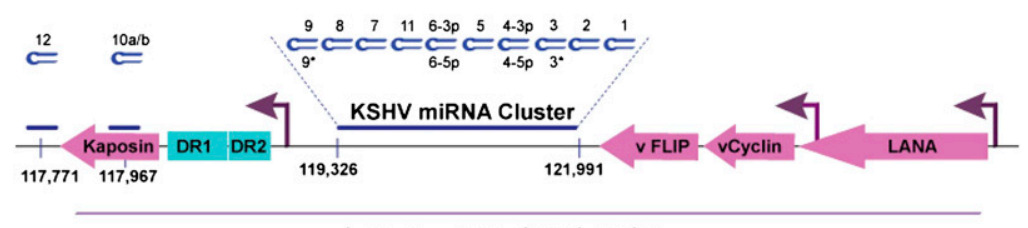

Latency associated region

B

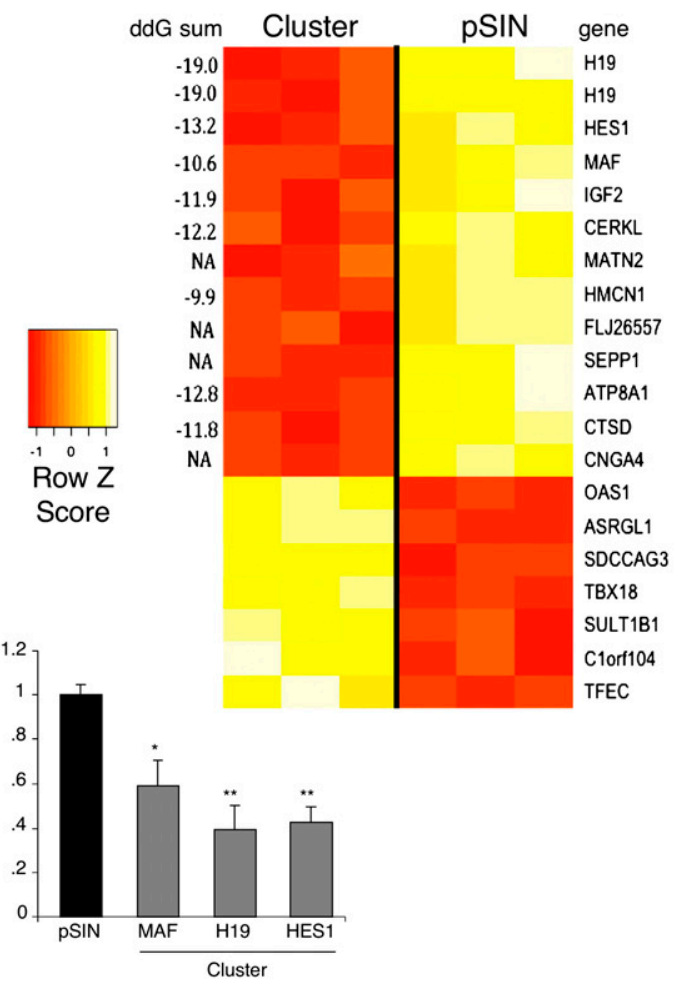

Figure 2. (A) Schematic representation of KSHV miRNA organization in the latency-associated region of the viral genome. The KSHV miRNAs are indicated by horizontal blue lines with the genomic locations noted below. Individual KSHV miRNA hairpins are shown above. Promoters are represented by dark-purple arrows, and protein-coding ORFs are shown in pink. The kaposin ORF is preceded by two sets of direct repeats (blue rectangles, DR1 and DR2). (B) Heat map of deregulated probes after transduction of LECs with either the KSHV miRNA cluster or empty vector (pSIN) $72 \mathrm{~h}$ post-infection. For all down-regulated probes (shown in red), a cumulative interaction score for the expressed KSHV miRNAs is shown (ddG sum). This set of most significantly different genes has a false discovery rate (Q value) of 0.13 . The $Z$-score scale shows mean-scaled and 0-centered $\log 2$ GEM expression values for each row. (C) mRNA down-regulation of the top three cellular genes identified in $B$, in LECs transduced with the miRNA cluster confirmed by qRT-PCR. Expression is relative to empty vector, $\mathrm{pSIN} .\left(^{\star}\right) P<0.01 ;\left(^{\star \star}\right) P<$ 0.001 . 
sum values represent energetically favorable interactions). Down-regulation by the KSHV miRNA cluster of the top three cellular genes-H19, HES1, and MAF-was confirmed by qRT-PCR (Fig. 2C). MAF was selected as a candidate miRNA target for further validation.

Previously, the transcription factor MAF was identified as a LEC-specific transcript (Petrova et al. 2002; Hong et al. 2004). MAF is involved in tissue specification and terminal differentiation of the lens, $\mathrm{T}$ cells, and endochondral bone (Kawauchi et al. 1999; Kim et al. 1999; Ring et al. 2000; MacLean et al. 2003). However, the function of MAF and its target genes in LECs is not known.

We identified 11 potential KSHV miRNA target sites in the MAF 3'UTR (Fig. 3A). Multiple viral miRNAs, some having more than one site, were predicted to target MAF. The location and degree of sequence complementation to the 3'UTR are shown (Supplemental Fig. 2D). miR-K12-6-5p had the strongest predicted site, and miRK12-6-3p had the only predicted target showing perfect sequence complementation across the entire seed region
(miRNA base pairs 2-9). The degree of sequence complementation between the miRNA seed region and the 3'UTR correlates with increased prediction ability and silencing via mRNA degradation (Bartel, 2009).

MAF mRNA was down-regulated in the presence of the KSHV miRNA cluster in both LECs and a stable 293 cell line (Fig. 3B). Western blotting confirmed MAF protein down-regulation in LECs transduced with the miRNA cluster (Fig. 3C). LECs expressing individual KSHV miRNAs identified miR-K12-6 and miR-K12-11 as cluster members capable of MAF silencing (Supplemental Fig. 2E). Although miR-K12-6 and miR-K12-11 induced MAF repression, the strongest down-regulation was caused by the entire cluster (Fig. 3B).

Next, we confirmed that MAF regulation was mediated through miRNA interactions with the 3'UTR. We cloned a fragment of the MAF 3'UTR, containing four predicted binding sites, downstream from a renilla reporter gene. Expression of miR-K12-1, miR-K12-6-5p, miR-K12-11, or the entire cluster induced a significant reduction in
A

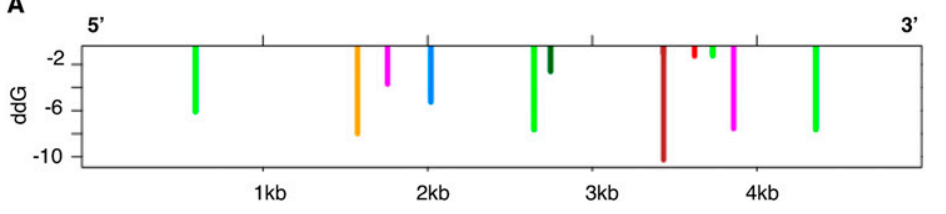

B
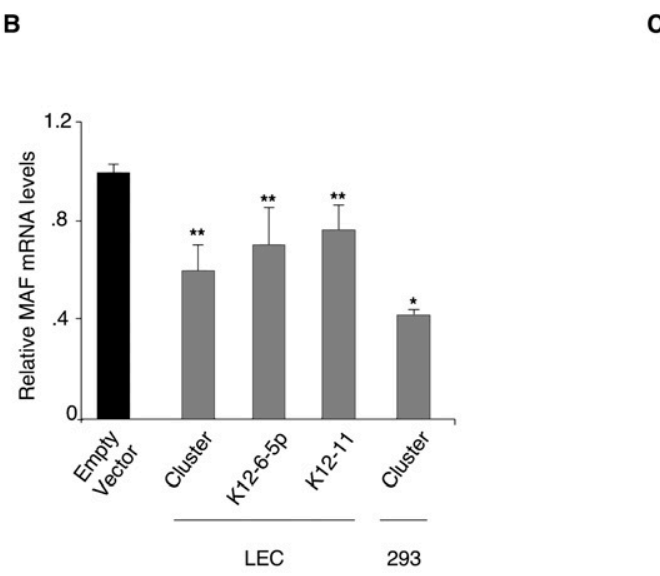

C
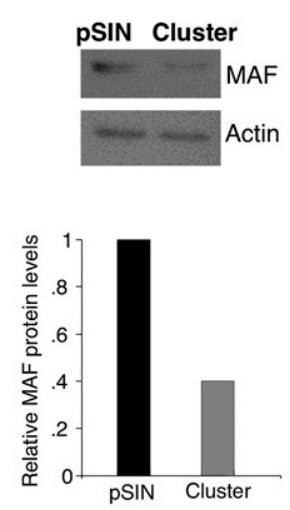

D

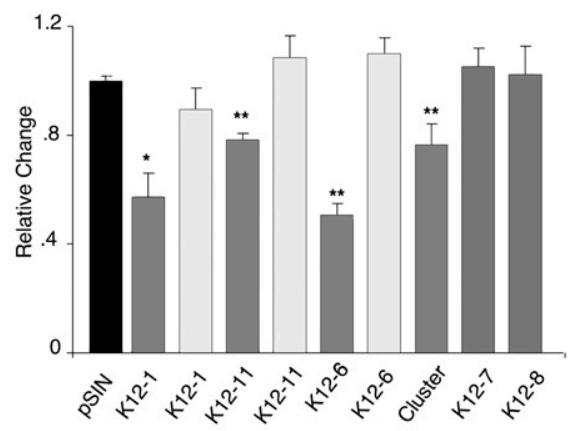

UTR

WT ++-+-+-+++
$\mathrm{K} 12-1$

K12-11

$\mathrm{K} 12-2$

K12-4-3p

K12-4-5p

K12-6-3p

K12-6-5p

Figure 3. MAF is a KSHV miRNA target. $(A)$ The positions of energetically favorable predicted seed site interactions of expressed KSHV miRNAs are shown for the MAF 3'UTR. On the $Y$-axis (ddG), the length of each line corresponds to the predicted strength of individual interactions: the more negative the value, the more energetically favorable the interaction. (B) MAF mRNA is down-regulated in the presence of the miRNA cluster, miR-K12-6, and miR-K12-11 (72 $\mathrm{h}$ post-infection), and in 293 cells stably expressing the cluster. All values are normalized to GAPDH. Relative to empty vector in the respective cell type, $P<$ $0.05\left(^{\star}\right)$ and $P<0.005\left(^{\star \star}\right)$. (C) Western blot analysis of MAF and loading control actin in LECs transduced with either miRNA cluster or pSIN (48 h post-infection). Quantification of relative intensity was performed by Scion Image software. $(D)$ KSHV miRNA-induced repression of the MAF 3'UTR. KSHV miRNAs were cotransfected with a MAF 3'UTR luciferase reporter plasmid. Either wild-type or mutated MAF 3'UTR was transfected. Mutated UTRs had the seed region of the corresponding miRNA disrupted by site-directed mutagenesis. The ratio of renilla to firefly luciferase relative light units was normalized to empty vector (pSIN) and the relative change is shown. Relative to pSIN cotransfected with wild-type MAF $3^{\prime} \mathrm{UTR}, P<0.05\left(^{\star}\right)$ and $P<0.005\left(^{\star \star}\right)$. 
renilla activity compared with empty vector control (Fig. 3D). Empty vector and two viral miRNAs (miR-K12-7 and miR-K12-8) with no predicted binding sites failed to induce silencing (Fig. 3D). Site-directed mutagenesis of KSHV miRNA predicted target sites in the MAF 3'UTR abolished silencing (Fig. 3D; Supplemental Fig. 2D), confirming that miR-K12-1, miR-K12-6-5p, and miR-K12-11 regulate MAF by interacting with the $3^{\prime} \mathrm{UTR}$. miR-K12-1 failed to induce MAF down-regulation when LECs were transduced with a lentivirus encoding for this miRNA (Supplemental Fig. 2E); however, when transfected miRK12-1, significantly reduced MAF 3'UTR luciferase reporter activity (Fig. 3D). This discrepancy may be due to higher miRNA expression levels in cells transfected with the miR-K12-1 plasmid; hence, silencing is only observed in the luciferase reporter assay. Therefore, we can neither confirm nor exclude miR-K12-1-mediated MAF silencing.

KSHV miR-K12-11 is a known ortholog of human miR-155 (Gottwein et al. 2007; Skalsky et al. 2007), a cellular miRNA shown to regulate MAF in $\mathrm{CD}^{+}$ T cells (Rodriguez et al. 2007). miR-155 is not expressed in KS (data not shown); however, our data indicate that KSHV-encoded miR-K12-11 mimics its function in LECs.
The specificity of MAF down-regulation by way of the KSHV miRNAs was confirmed using antagomirs in 293 cells stably expressing the miRNA cluster. miR-K12-6-5p and miR-K12-11 inhibitors both caused a significant increase in MAF mRNA in cells expressing the miRNA cluster (Supplemental Fig. 3B). In contrast, an inhibitor against miR-K12-11 had no effect on MAF mRNA levels in control cell lines (Supplemental Fig. 3B). We observed an increase in MAF mRNA when control cells were transfected with an inhibitor against miR-K12-6 (Supplemental Fig. 3B). However, unlike the cluster plus inhibitor 6, this effect was not significant.

\section{$M A F$ is down-regulated during primary KSHV infection}

MAF (also referred to as c-Maf) belongs to the AP1 superfamily of basic leucine zipper (bZIP) proteins, and is the founding member of the Maf family of transcription factors (Nishizawa et al. 1989). To determine whether MAF, or any of the other family members, were deregulated during primary KSHV infection, we compared the gene expression profile of infected and noninfected LECs. MAF is the only Maf transcription factor that decreased upon primary infection (Fig. 4A). In addition, we observed
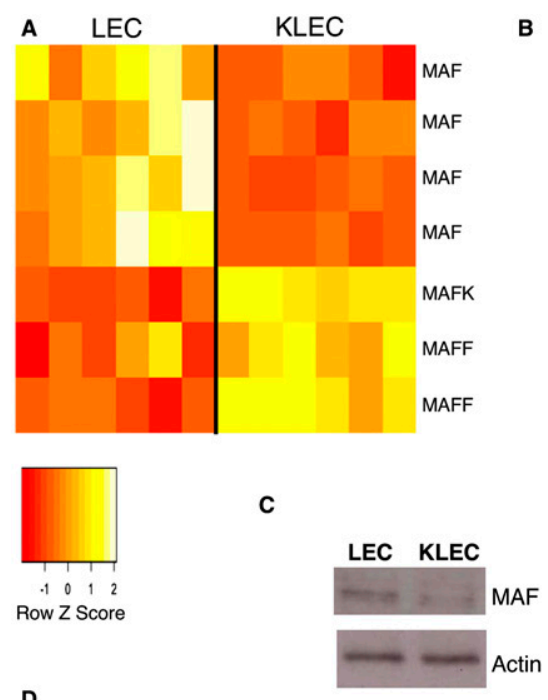

D

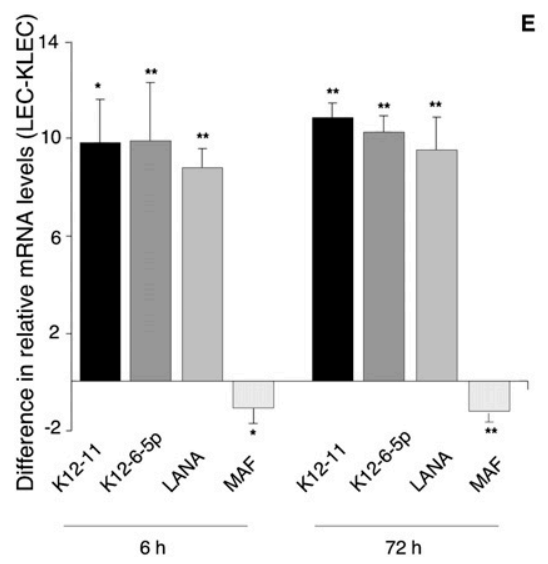

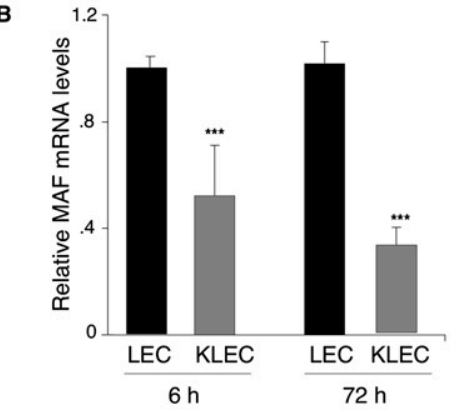

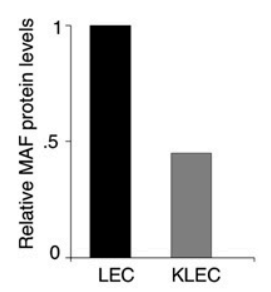

E

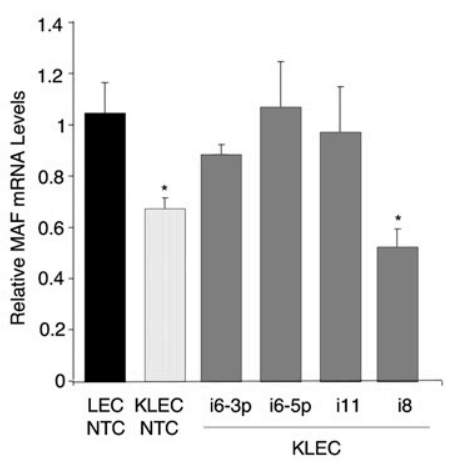

Figure 4. MAF is down-regulated during primary KSHV infection. (A) MAF mRNA was down-regulated in LECs $72 \mathrm{~h}$ post-KSHV infection (KLEC). The heat map shows the $Z$-score of the GEM data in which each normalized expression value is divided by the mean and centered around $0(n=6)$. Downregulated probes are shown in red, and up-regulated probes are shown in yellow. (B) MAF mRNA downregulation at 6 and $72 \mathrm{~h}$ post-KSHV infection of LECs, as quantified by qRT-PCR. Relative to noninfected LECs at the equivalent time point, $P<0.05$ $\left({ }^{\star}\right)$ and $P<0.001\left(^{\star \star}\right) .(C)$ Western blot analysis of MAF and loading control actin protein in noninfected and KSHV-infected LECs (KLEC; 48 h postinfection). Quantification of relative intensity was performed by Scion Image software. $(D)$ The graph shows the relative change in expression of each gene before (LEC) and after KSHV infection of LECs (KLEC) at 6 and $72 \mathrm{~h}$ post-infection. KSHV viral gene expression was confirmed by qRT-PCR for LANA. Expression is relative to GAPDH; the bars show the average $(n=3)$ difference in relative expression between LECs and KLECs $(\Delta \Delta \mathrm{Ct}=\Delta \mathrm{Ct}$ LEC $-\Delta \mathrm{Ct}$ KLEC). $\left({ }^{\star}\right) P<0.001$; $\left(^{\star \star}\right) P<0.005$. (E) Inhibition of miR-K12-6 and miR-K12-11 attenuates MAF silencing. LECs were infected with KSHV in the presence of LNA inhibitors against miR-K12-11, miR-K12-6-3p, miR-K12-6-5p, miR-K12-8, or a nontargeting control (NTC). MAF mRNA is significantly reduced in the presence of a NTC or miR-K12-8, a nontargeting KSHV miRNA. When miR-K12-11 and both mature isoforms of miR-K12-6 were inhibited, KSHV infection failed to induce MAF down-regulation. Error bars correspond to standard error. $\left(^{\star}\right) P<0.05$. 
a significant up-regulation of two other Maf transcription factors: MAFF and MAFK (Fig. 4A). MAF mRNA suppression occurs early during primary infection; downregulation then increased and was sustained up to $72 \mathrm{~h}$ post-KSHV infection (Fig. 4B). Decreased mRNA abundance led to reduced MAF protein levels in KSHVinfected cells compared with noninfected LECs (Fig. 4C). Viral miRNAs miR-K12-6-5p and miR-K12-11 were detected $6 \mathrm{~h}$ post-KSHV infection, as was LANA mRNA (Fig. 4D). miRNA expression increased at $72 \mathrm{~h}$ postinfection, correlating with an increased down-regulation of MAF mRNA (Fig. 4D).

To confirm that MAF down-regulation was by way of KSHV miRNA-mediated silencing-in particular, miRK12-6 and miR-K12-11-we inhibited these miRNAs during primary infection. miRNAs were inhibited using LNA-modified oligonucleotides complementary to the mature miRNA sequence. KSHV infection failed to induce MAF mRNA suppression in the presence of inhibitors against miR-K12-11 or miR-K-12-6 (Fig. 4E). In contrast, inhibition of miR-K12-8, a miRNA not predicted to target MAF, had no effect on MAF mRNA levels. We thus confirmed that MAF silencing is mediated specifically by miR-K12-6 and miR-K12-11. Interestingly, inhibition of both mature isoforms of miR-12-6 led to an increase in MAF mRNA (Fig. 4E), suggesting that both branches of the stem-loop contribute to MAF down-regulation, which concurs with the in silico target prediction analysis (Fig. 3A).

\section{$M A F$ represses BEC marker genes in LECs}

To determine whether MAF down-regulation played a role in $\mathrm{KSHV}$-induced endothelial reprogramming, we studied the expression of BEC-specific genes, which are known to increase upon KSHV infection of LECs. BECspecific genes were identified as those expressed in BECs, but not LECs, using our previous GEM analysis (Lagos et al. 2007; Supplemental Table 2). We analyzed data from three independent GEM data sets where we observed suppression of MAF in LECs: KSHV-infected versus noninfected LECs, LECs transduced with the KSHV miRNA cluster versus empty lentiviral vector, and LECs transfected with siRNA targeting MAF versus nontargeting siRNA control.

Gene set enrichment analysis (GSEA) (Subramanian et al. 2005) identified a significant and concordant increase in expression of BEC-specific genes across all three GEM data sets (Fig. 5A). This concordant change indicated that the KSHV miRNAs could contribute to the control of BEC markers through suppression of the transcription factor MAF.

We compared the leading-edge genes (i.e., those genes most highly up-regulated) within each GSEA analysis to identify those regulated by MAF within our BEC marker set (Supplemental Fig. 4A). Three putative MAF targets were highly up-regulated after KSHV infection, expression of the miRNA cluster, and siRNA knockdown of MAF: TFEC, NRCAM, and SLC1A1. Another gene, HDAC9, was one of the most highly up-regulated genes after KSHV infection and MAF siRNA knockdown, and it was also upregulated by the miRNA cluster, although not present in the leading edge (Supplemental Fig. 4A). qRT-PCR confirmed the up-regulation of these candidate MAF target genes by the KSHV miRNAs and after siRNA-mediated MAF silencing (Fig. 5B). To confirm that the KSHV miRNAs regulate $\mathrm{BEC}$-specific genes by way of MAF silencing, we overexpressed the MAF ORF, without its 3'UTR, in the presence of the miRNA cluster. Exogenous MAF ablated the miRNA cluster-induced up-regulation of the four identified BEC-specific genes (Fig. 5C). Moreover, we showed that MAF regulated the transcription of additional known BEC markers (MAML2, FLT1, CXCR4, and CXCL12). We confirmed their significant up-regulation after MAF silencing by siRNA in LECs (Supplemental Fig. 4B).

MAF is differentially expressed between LECs and BECs (Supplemental Fig. 5A). MAF levels in BECs were similar to PROX1, the master regulator of LEC differentiation (Wigle and Oliver 1999; Wigle et al. 2002). In contrast, the MAF targets genes we identified were more highly expressed in BECs compared with LECs (Supplemental Fig. 5A). Exogenous MAF expression in BECs led to suppression of these MAF targets (Fig. 6A). MAF expression in BECs also repressed additional known BECspecific genes: FLT1, CXCR4, and CXCL12 (Fig. 6A). MAF overexpression in BECs was confirmed by Western blotting (Fig. 6B).

MAF and PROX1 are both highly expressed in the lens, where PROX1 was shown previously to enhance MAF activation of $\beta$-crystallin transcription (Chen et al. 2002; Cui et al. 2004). However, the mechanism behind MAF and PROX1 cooperation is unclear, and direct interaction has not been demonstrated. Petrova et al. (2002) observed a set of 63 genes that were repressed in BECs following PROX1 overexpression. Many of the same genes were enriched in LECs following siMAF knockdown (Supplemental Fig. 5B). Furthermore, similar to our data on MAF, PROX1 has been shown to suppress expression of BEC markers in LECs (Johnson et al. 2008). Due to the LECspecific expression of both MAF and PROX1, we could envisage that these transcription factors form a repressor complex, suppressing BEC markers to maintain the LEC phenotype.

\section{Discussion}

KSHV induces transcriptional reprogramming upon infection of LECs (Wang et al. 2004). Our study shows that multiple KSHV-encoded miRNAs-in particular, miR-K12-11 and miR-K12-6-function in concert to target the LEC-specific transcription factor MAF to modulate LEC fate during infection (Fig. 7). Therefore, these findings show that the KSHV miRNAs contribute in part to the mechanism underlying viral-induced reprogramming.

Previous studies confirmed the expression of a subset of viral miRNAs in KS (O'Hara et al. 2009). Here we validate KSHV miRNA expression in KS lesions, confirming that the majority of viral miRNAs are expressed and therefore are likely to be relevant to KS oncogenesis. 
A

A

B
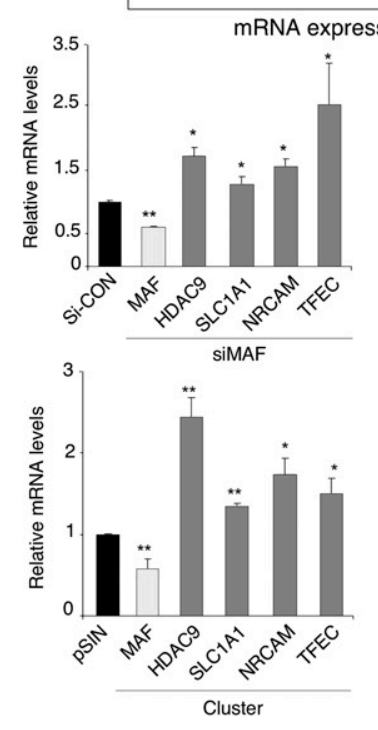

$$
\text { D }
$$
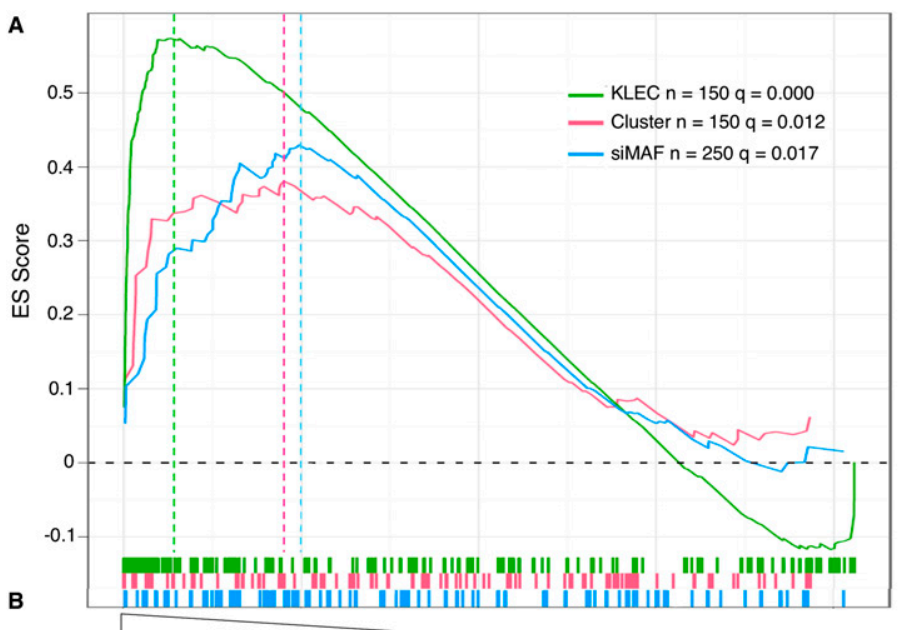

ression rank of BEC specific genes

$$
c
$$

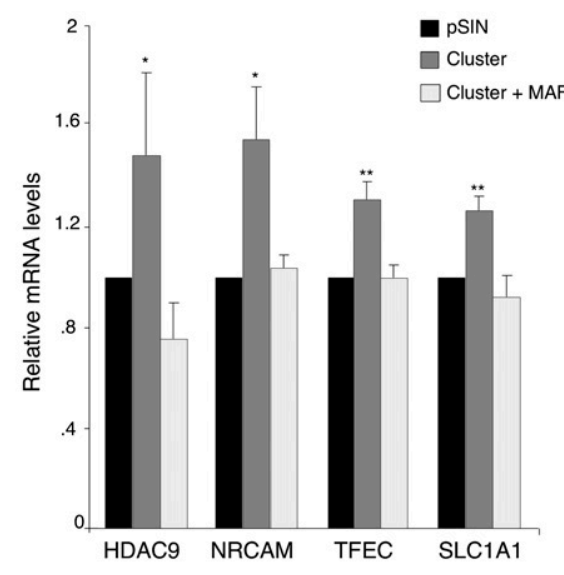

Figure 5. MAF down-regulation contributes to transcriptional reprogramming of LECs. (A) GSEA demonstrates a significant enrichment of BEC markers in three different GEM experiments: LECs infected with KSHV (KLEC, green line), LECs transfected with siRNA against MAF (siMAF, blue), and LECs infected with the KSHV miRNA cluster (pink). We tested several lists of the topmost BEC markers (top 50, 100, $150,200,250,300)$ and plotted the most significant list for each experiment. All curves display a similar skewed distribution to the right, indicating increased expression. Vertical lines below the plots represent BEC-specific probes. Hatched lines represent the leading-edge gene set for each experiment. The significance calculation shown (q) is a false discovery rate. (B) qRT-PCR analysis confirmed the up-regulation of candidate MAF target genes identified by GSEA. MAF down-regulation by siRNA and miRNA cluster is shown (light-gray bars). All values were normalized to GAPDH. In each condition, expression is relative to the corresponding control siCON or pSIN. $\left(^{\star}\right) P<0.05 ;\left(^{\star \star}\right) P<0.005$. (C) Exogenous MAF lacking the $3^{\prime} \mathrm{UTR}$ suppressed miRNA clusterinduced up-regulation of candidate MAF target genes. MAF target genes were up-regulated in LECs transduced with the KSHV miRNA cluster as confirmed by qRT-PCR (dark-gray bars). Coinfection with cluster and lentivirus expressing the MAF ORF abolished this up-regulation (light-gray bars). The experiment was performed three times; a representative experiment is shown. Comparing KSHV cluster to pSIN, $P<0.05\left(^{\star}\right)$ and $P<0.005\left({ }^{\star \star}\right)$. Differences between LECs transduced with cluster plus MAF and pSIN were not significant.
In order to elucidate the role of viral miRNAs during infection, it is necessary to identify their targets. Specifically, we sought to identify genes deregulated upon miRNA expression in LECs, as these are the endothelial cell type most closely related to KS tumor (spindle) cells (Wang et al. 2004). Our gene expression microarray approach identified a cohort of genes significantly downregulated in the presence of the KSHV miRNA cluster, which encodes 14 out of the 17 KSHV mature miRNAs. Although useful in detecting cellular genes silenced by miRNA degradation, additional proteomic approaches will be necessary to detect those KSHV miRNA targets regulated by translation inhibition (Mathonnet et al. 2007).

The bZIP transcription factor MAF was selected as a candidate miRNA target for further validation. Although originally classified as a transforming oncogene (Nishizawa et al. 1989; Kawai et al. 1992), MAF has subsequently been shown to mediate terminal differentiation of a range of cell types (Eychene et al. 2008). We therefore hypothesized that MAF may be involved in endothelial differentiation, and that deregulation of this transcription factor could play a role in KSHV-mediated reprogramming. KSHV miRNA cluster-induced MAF down-regulation was confirmed at both the RNA and protein levels. Multiple KSHV miRNAbinding sites were identified spanning the MAF 3'UTR, with miR-K12-6 and miR-K12-11 both having more than one predicted site. Lentiviral expression of individual viral miRNAs and MAF 3'UTR luciferase reporter assays confirmed miR-K12-6 and miR-K12-11 as cluster members capable of silencing MAF. This is in keeping with other validated miRNAs targets, whereby a single cellular gene is targeted by multiple KSHV miRNAs (Samols et al. 2007; Ziegelbauer et al. 2009). Site-directed mutagenesis of predicted binding sites abolished KSHV miRNA-induced MAF silencing; confirming regulation is mediated through interactions with the $3^{\prime} \mathrm{UTR}$.

MAF down-regulation occurs early and is maintained during whole-virus infection; silencing coincides with expression of the viral miRNAs. Inhibition of miR-K12-6 and miR-K12-11 during primary KSHV infection prevented MAF silencing, restoring MAF mRNA levels to those comparable with noninfected cells. In contrast, inhibition of miR-K12-8, which does not silence MAF, had no effect on MAF mRNA levels. This work confirms MAF 


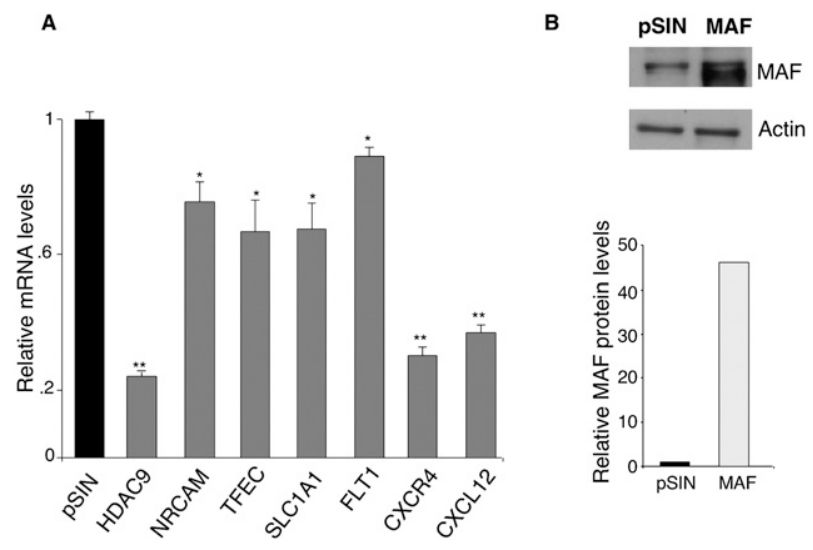

Figure 6. MAF represses BEC markers. (A) In BECs, exogenous MAF represses MAF target genes. qRT-PCR analysis of BEC marker genes in BECs transduced with pSIN or MAF lentivirus. Values normalized to GAPDH and relative to empty vector, pSIN. $\left(^{\star}\right) P<0.05$; $\left.{ }^{* \star}\right) P<0.005$. (B) Western blot analysis of MAF and loading control actin protein in LECs transduced with either empty lentiviral vector (pSIN) or MAF-expressing lentivirus (MAF).

down-regulation during KSHV infection is mediated by several viral miRNAs. miRNA target sites located within 40 base pairs (bp) of each other have been shown to act cooperatively during silencing, whereas sites further apart act independently (Grimson et al. 2007; Baek et al. 2008). Since none of the KSHV miRNA target sites are closely situated, MAF silencing by multiple viral miRNAs is likely to be additive; further experimental work is needed to confirm this.

In concordance with its role in tissue differentiation, MAF regulates distinct target genes in different cell types (Hegde et al. 1999; Kim et al. 1999; Ring et al. 2000; Aziz et al. 2009). We identified a cohort of potential MAF target genes through GEM analysis of LECs in which MAF had been silenced. In this context, we observed a significant up-regulation of genes associated with BEC differentiation status. Therefore, it appears that, in LECs,
MAF functions as a transcriptional repressor. MAF contains a transactivation domain, and the majority of studies into its function show MAF to be a transcriptional activator. However, our work is consistent with reports showing that MAF can also function as a repressor (Dhakshinamoorthy and Jaiswal 2002; Aziz et al. 2009) .

LEC identity is initiated by expression of PROX1 in a subset of venous endothelial cells during embryogenesis (Wigle and Oliver 1999; Wigle et al. 2002). Furthermore, sustained PROX1 expression is necessary in the adult mouse to maintain the LEC phenotype; otherwise, cells revert to the default blood vessel endothelial state (Johnson et al. 2008). Here we identify a role for MAF in suppressing BEC markers, thus also contributing to LEC identity. KSHV causes transcriptional reprogramming during infection, whereby infected LECs or BECs are more similar to each other than their noninfected counterparts. KSHV miRNA silencing of MAF, and the subsequent increase in BEC marker expression, explain in part the mechanism behind this reprogramming. Although, overall, the poorly differentiated KS tumor cells are most similar to LECs (Wang et al. 2004), our findings provide a potential explanation for their BEC-like characteristics. Future work will delineate the relationship between MAF and PROX1 in the maintenance of LEC identity.

Together our results provide insight into the function of the KSHV miRNAs, identify a novel role for viral miRNAs in regulating the cellular differentiation state, and identify MAF as a transcription factor involved in the plasticity of LECs and BECs.

\section{Materials and methods}

\section{Cell culture}

LECs were cultured as described previously (Lagos et al. 2007). LECs were used for experiments at passages 3-7. 293T and HeLa cells were cultured in Dulbecco's modified Eagle medium (Invitrogen) supplemented with 10\% FCS (Sigma). BECs were isolated from myometrium, and cells were cultured as described previously (Nikitenko et al. 2006). 293 cell lines were cultured as above but with $100 \mu \mathrm{g} / \mathrm{mL}$ geneticin (Invitrogen). BCLB-1 cells

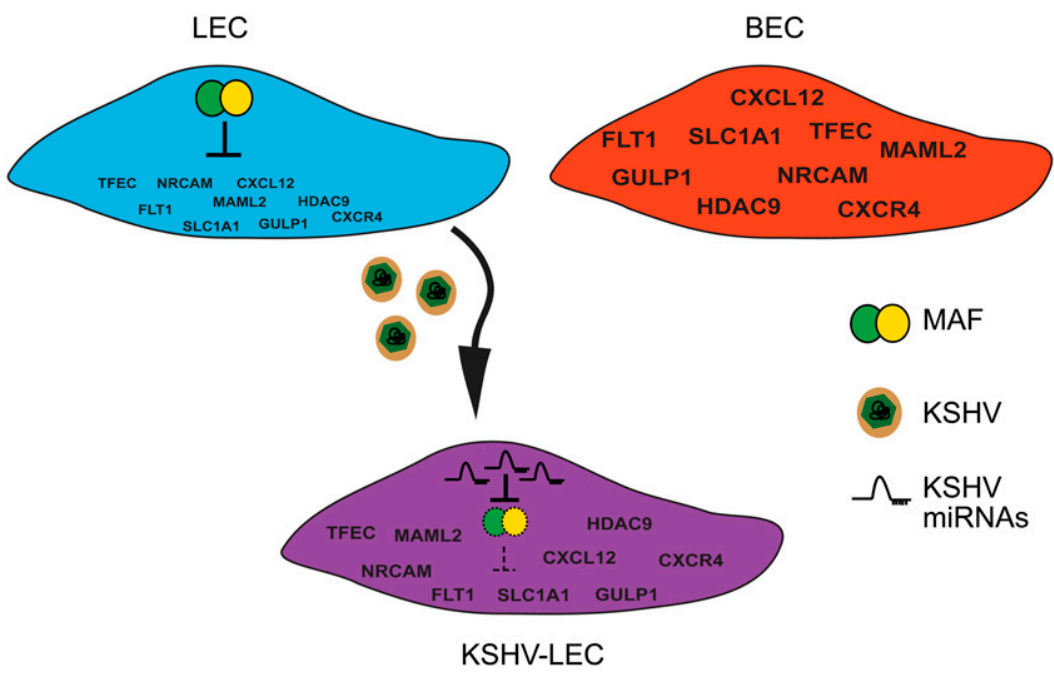

Figure 7. KSHV miRNAs contribute to LEC reprogramming. MAF represses the transcription of BEC marker genes in LECs (blue cell). BEC markers, but not MAF, are expressed in BECs (red cell). Upon KSHV infection and expression of the viral miRNAs, MAF is silenced (purple cell), leading to increased expression of BEC marker genes. The resulting KSHV-infected LEC is more similar to BECs than a noninfected cell. BEC marker gene names are shown in blue. 
latently infected with recombinant GFP-KSHV (Wang et al. 2004) were cultured in RPMI 1640 (Invitrogen) supplemented with $10 \%$ FCS and $400 \mathrm{ng} / \mathrm{mL}$ geneticin (Invitrogen).

\section{KSHV production and infection of LECS}

KSHV was produced as described, and LECs were infected with 250-500 viral copies per cell (Wang et al. 2004). This procedure reproducibly resulted in $30 \%-50 \%$ of LECs expressing GFP at $24 \mathrm{~h}$ and $72 \mathrm{~h}$ post-infection, respectively, as measured by flow cytometry.

\section{Western blotting}

Forty-eight hours post-infection with either lentivirus or KSHV, LECs were lysed in RIPA buffer and equal concentrations of protein were resolved on a gel. Antibodies against MAF (Imgenex, IMG-6076A) and actin (Calbiochem, CP01) were detected with HRP-conjugated secondary antibodies and were quantified using ECL (GE Healthcare).

\section{Subcloning of KSHV miRNAs into pSIN-MCS}

The KSHV miRNA cluster and individual miRNAs were cloned into pcDNA3.1/V5/HisA as described (Samols et al. 2007). The cluster and individual miRNAs were subcloned into the lentiviral vector pSIN-MCS, derived from pCSGW as described (Vart et al. 2007).

\section{Lentivirus production and infection of LECs}

Lentivirus was produced as described previously (Vart et al. 2007). LECs were harvested $3 \mathrm{~d}$ post-infection.

\section{$q P C R$ and $q R T-P C R$}

Genomic DNA for qPCR was extracted using the QIAamp DNA mini-kit (Qiagen). The number of lentiviral copies per cell (c/c) was determined as described previously (Vart et al. 2007). Total RNA was extracted using either RNeasy mini-kit or miRNeasy mini-kit (Qiagen). qRT-PCR quantification of GAPDH and LANA mRNA was performed as described previously (Vart et al. 2007). All other mRNAs were quantified using commercially available TaqMan Gene Expression assay (Applied Biosystems).

cDNA synthesis for qRT-PCR quantification of mature miRNAs was performed using the TaqMan miRNA Reverse Transcription Kit (Applied Biosystems) according to the manufacturer's instructions. Custom TaqMan miRNA Assays were designed against the mature miRNA sequence as detailed in miRBase version 13.0. Cellular small nucleolar RNA RNU66 was used as a reference RNA.

\section{Luciferase reporter assays}

miRNA activity from pSIN-Cluster was quantified using miRNA sensor vectors pGL3-miR1 or pGL3-miR11 as described previously (Samols et al. 2005). The first $2.3 \mathrm{~kb}$ of the MAF 3'UTR were cloned into the psiCheck-2 renilla reporter plasmid (Promega). Site-directed mutagenesis of the KSHV miRNA-binding sites in the MAF 3'UTR was performed using QuikChange II XL Site-Directed Mutagenesis Kit (Stratagene). A distinct mutated UTR was made for miR-K12-6-3p, miR-K12-11, and miR-K12-1. Successful mutagenesis was confirmed by sequencing. The reporter plasmid (50 ng) was cotransfected with the KSHV miRNAs or empty lentiviral vector (500 ng) in $2.5 \times 10^{4} \mathrm{HeLa}$ cells. Forty-eight hours post-transfection, cells were harvested and the luciferase activity was measured using a Fluoroskan Ascent FL luminometer (Thermo Fisher Scientific, Inc.). Renilla activity was normalized to internal firefly luciferase levels.

\section{Gene expression and miRNA microarray profiling}

Gene expression profiling was performed using the Human Genome U133 Plus 2.0 Array (Affymetrix). Total RNA was extracted from subconfluent LECs (passage 4) infected with lentivirus expressing the miRNA cluster or empty vector (average of 12.7 copies per cell). Similarly, total RNA was extracted $48 \mathrm{~h}$ post-transfection from subconfluent LECs transfected with MAF On-Target Plus SMARTpool or the On-Target plus Nontargeting Pool (Thermo Fisher Scientific, Inc.). We previously generated gene expression microarray data of KSHV-infected and noninfected LECs (Lagos et al. 2007).

Fresh frozen KS and skin biopsies were obtained from the NIH AIDS Cancer Specimen Resource Bank, and from Chelsea and Westminster Hospital. All participants were male, HIV-infected, and between the ages of 26 and 58 years old. All participants were undergoing anti-retroviral treatment at the time of collection. RNA was extracted using the miRNeasy mini-kit (Qiagen).

The small RNA fraction was assessed using the Agilent small RNA kit. Quality and integrity of the RNA fraction between 6 and 150 nucleotides was quantified using the Agilent 2100 bioanalyzer (Agilent). One-hundred nanograms of total RNA per sample were hybridized to the Agilent Human miRNA microarray according to the manufacturer's instructions.

\section{GEM accession numbers}

GEM expression data were deposited with the NCBI Gene Expression Omnibus database (http://www.ncbi.nlm.nih.gov/ geo): KLEC, GSE16357; miRNA cluster, GSE16355; miRNA KS, GSE16353; and siMAF, GSE16356.

\section{KSHV miRNA inhibition}

KSHV miRNAs were inhibited using LNA-modified oligonucleotides from Exiqon. LECs $\left(2 \times 10^{4}\right)$ were transfected in OptiMEM (Invitrogen) using oligofectamine (Invitrogen), with $50 \mathrm{nM}$ inhibitors designed against the mature miRNA sequence of K126-3p, K12-6-5p, K12-8, K12-11, or a nontargeting control. Cells were incubated for $5 \mathrm{~h}$ in the transfection mixture; $1 \mathrm{~mL}$ of LEC media was then added per well. Twenty-four h post-transfection, cells were washed and media were changed. Forty-eight hours post-transfection, LECs were infected with KSHV; 24 h postinfection, cells were harvested, and MAF mRNA levels were assessed by qRT-PCR.

\section{Statistical analysis}

Gene expression and miRNA microarray GEM and miRNA analysis were carried out using Bioconductor packages for the R statistical programming language (Gentleman et al. 2004). For Affymetrix GEM, the affyPLM package was used for quality control, the robust multiarray algorithm (rma) from the affy package was used for preprocessing, and the limma package was used to determine differential gene expression (Smyth, 2004). For Agilent miRNA arrays, we extracted the median (gMedianSignal) and background signal (gBGUsed). The arrays were then background-corrected using the "normexp" function (Ritchie et al. 2007) of the limma package and quantile-normalized to each other. The replicate probes were averaged and, for Figure 1A, the median of the remaining pseudoreplicates was used (i.e., usually four distinct probes per miRNA). 
miRNA target prediction analysis The PITA algorithm (Kertesz et al. 2007) was used to calculate both a single miRNA-to-target interaction score (ddG) and a cumulative score for multiple miRNA-to-target interactions using the recommended formula (http://genie.weizmann.ac.il/pubs/mir07/mir07_notes.html): ddGsum $=-\log \left[\Sigma\left(\mathrm{e}^{-\mathrm{ddG}}\right)\right]$.

Potential interactions are 8mers with at most either one G:U wobble or one mismatch (but not both). Here we calculated cumulative interaction scores including only the KSHV miRNA that we found to be significantly expressed (in AIDS-KS relative to skin). Target 3'UTR sequences from genes that were downregulated upon KSHV miRNA expression in LECs were obtained from Ensembl (http://www.ensembl.org/Multi/martview).

GSEA GSEA measures the enrichment of a gene set within a GEM experiment (Subramanian et al. 2005). The enrichment score (ES) is a metric of the skew of a gene set within the rank of genes sorted by their GEM expression difference. The significance of enrichment ( $\mathrm{q}$, or false discovery rate) is the proportion of true ES >1000 ES generated from random gene sets (of equal size) (e.g., proportion of ES ${ }^{\mathrm{OBSERVED}}>\mathrm{ES}^{\mathrm{NULL}}$ ). Leading-edge genes are the subset that contributes most to the ES.

For all experiments, bars represent the average of three experiments and error bars correspond to standard deviation. $P$-values were calculated using a two-tailed Student's $t$-test, unless stated otherwise.

\section{Acknowledgments}

We thank all members of the Boshoff laboratory-in particular, Dr. Emuss-for helpful discussions; the U.S. AIDS cancer specimen resource bank (ACSR) for KS biopsies; and N. Patel and R. Robey for biopsy collections. This work was funded through grants from the MRC and Cancer Research UK.

\section{References}

Aziz A, Soucie E, Sarrazin S, Sieweke MH. 2009. MafB/c-Maf deficiency enables self-renewal of differentiated functional macrophages. Science 326: 867-871.

Baek D, Villen J, Shin C, Camargo FD, Gygi SP, Bartel DP. 2008. The impact of microRNAs on protein output. Nature 455: 64-71.

Bartel DP. 2009. MicroRNAs: Target recognition and regulatory functions. Cell 136: 215-233.

Bixel MG, Adams RH. 2008. Master and commander: Continued expression of Proxl prevents the dedifferentiation of lymphatic endothelial cells. Genes \& Dev 22: 32323235.

Boshoff C, Weiss R. 2002. AIDS-related malignancies. Nat ReV Cancer 2: 373-382.

Boshoff C, Schulz TF, Kennedy MM, Graham AK, Fisher C, Thomas A, McGee JO, Weiss RA, O'Leary JJ. 1995. Kaposi's sarcoma-associated herpesvirus infects endothelial and spindle cells. Nat Med 1: 1274-1278.

Cai X, Lu S, Zhang Z, Gonzalez CM, Damania B, Cullen BR. 2005. Kaposi's sarcoma-associated herpesvirus expresses an array of viral microRNAs in latently infected cells. Proc Natl Acad Sci 102: 5570-5575.

Carroll PA, Brazeau E, Lagunoff M. 2004. Kaposi's sarcomaassociated herpesvirus infection of blood endothelial cells induces lymphatic differentiation. Virology 328: 7-18.

Chang Y, Cesarman E, Pessin MS, Lee F, Culpepper J, Knowles DM, Moore PS. 1994. Identification of herpesvirus-like DNA sequences in AIDS-associated Kaposi's sarcoma. Science 266: 1865-1869.
Chen Q, Dowhan DH, Liang D, Moore DD, Overbeek PA. 2002. CREB-binding protein/p300 co-activation of crystallin gene expression. J Biol Chem 277: 24081-24089.

Chen CZ, Li L, Lodish HF, Bartel DP. 2004. MicroRNAs modulate hematopoietic lineage differentiation. Science 303: 83-86.

Cui W, Tomarev SI, Piatigorsky J, Chepelinsky AB, Duncan MK. 2004. Mafs, Prox1, and Pax6 can regulate chicken $\beta B 1$ crystallin gene expression. J Biol Chem 279: 11088-11095.

Dhakshinamoorthy S, Jaiswal AK. 2002. c-Maf negatively regulates ARE-mediated detoxifying enzyme genes expression and anti-oxidant induction. Oncogene 21: 5301-5312.

Dupin N, Fisher C, Kellam P, Ariad S, Tulliez M, Franck N, van Marck E, Salmon D, Gorin I, Escande JP, et al. 1999. Distribution of human herpesvirus-8 latently infected cells in Kaposi's sarcoma, multicentric Castleman's disease, and primary effusion lymphoma. Proc Natl Acad Sci 96: 45464551.

Eychene A, Rocques N, Pouponnot C. 2008. A new MAFia in cancer. Nat Rev Cancer 8: 683-693.

Gentleman RC, Carey VJ, Bates DM, Bolstad B, Dettling M, Dudoit S, Ellis B, Gautier L, Ge Y, Gentry J, et al. 2004. Bioconductor: Open software development for computational biology and bioinformatics. Genome Biol 5: R80. doi: 10.1186/ gb-2004-5-10-r80.

Gottwein E, Cai X, Cullen BR. 2006. A novel assay for viral microRNA function identifies a single nucleotide polymorphism that affects Drosha processing. I Virol 80: 5321-5326.

Gottwein E, Mukherjee N, Sachse C, Frenzel C, Majoros WH, Chi JT, Braich R, Manoharan M, Soutschek J, Ohler U, et al. 2007. A viral microRNA functions as an orthologue of cellular miR-155. Nature 450: 1096-1099.

Grimson A, Farh KK, Johnston WK, Garrett-Engele P, Lim LP, Bartel DP. 2007. MicroRNA targeting specificity in mammals: Determinants beyond seed pairing. Mol Cell 27: 91105.

Gu S, Jin L, Zhang F, Sarnow P, Kay MA. 2009. Biological basis for restriction of microRNA targets to the $3^{\prime}$ untranslated region in mammalian mRNAs. Nat Struct Mol Biol 16: 144150.

Hegde SP, Zhao J, Ashmun RA, Shapiro LH. 1999. c-Maf induces monocytic differentiation and apoptosis in bipotent myeloid progenitors. Blood 94: 1578-1589.

Hong YK, Foreman K, Shin JW, Hirakawa S, Curry CL, Sage DR, Libermann T, Dezube BJ, Fingeroth JD, Detmar M. 2004. Lymphatic reprogramming of blood vascular endothelium by Kaposi sarcoma-associated herpesvirus. Nat Genet 36: 683685.

Johnson NC, Dillard ME, Baluk P, McDonald DM, Harvey NL, Frase SL, Oliver G. 2008. Lymphatic endothelial cell identity is reversible and its maintenance requires Proxl activity. Genes \& Dev 22: 3282-3291.

Kahn HJ, Bailey D, Marks A. 2002. Monoclonal antibody D2-40, a new marker of lymphatic endothelium, reacts with Kaposi's sarcoma and a subset of angiosarcomas. Mod Pathol 15: 434-440.

Kawai S, Goto N, Kataoka K, Saegusa T, Shinno-Kohno H, Nishizawa M. 1992. Isolation of the avian transforming retrovirus, AS42, carrying the v-maf oncogene and initial characterization of its gene product. Virology 188: 778-784.

Kawauchi S, Takahashi S, Nakajima O, Ogino H, Morita M, Nishizawa M, Yasuda K, Yamamoto M. 1999. Regulation of lens fiber cell differentiation by transcription factor c-Maf. J Biol Chem 274: 19254-19260.

Kertesz M, Iovino N, Unnerstall U, Gaul U, Segal E. 2007. The role of site accessibility in microRNA target recognition. Nat Genet 39: 1278-1284. 
Kim JI, Ho IC, Grusby MJ, Glimcher LH. 1999. The transcription factor c-Maf controls the production of interleukin-4 but not other Th2 cytokines. Immunity 10: 745-751.

Lagos D, Trotter MW, Vart RJ, Wang HW, Matthews NC, Hansen A, Flore O, Gotch F, Boshoff C. 2007. Kaposi sarcoma herpesvirus-encoded vFLIP and vIRF1 regulate antigen presentation in lymphatic endothelial cells. Blood 109: 15501558.

MacLean HE, Kim JI, Glimcher MJ, Wang J, Kronenberg HM, Glimcher LH. 2003. Absence of transcription factor c-maf causes abnormal terminal differentiation of hypertrophic chondrocytes during endochondral bone development. Dev Biol 262: 51-63.

Mathonnet G, Fabian MR, Svitkin YV, Parsyan A, Huck L, Murata T, Biffo S, Merrick WC, Darzynkiewicz E, Pillai RS, et al. 2007. MicroRNA inhibition of translation initiation in vitro by targeting the cap-binding complex eIF4F. Science 317: 1764-1767.

Nikitenko LL, Cross T, Campo L, Turley H, Leek R, Manek S, Bicknell R, Rees MC. 2006. Expression of terminally glycosylated calcitonin receptor-like receptor in uterine leiomyoma: Endothelial phenotype and association with microvascular density. Clin Cancer Res 12: 5648-5658.

Nishizawa M, Kataoka K, Goto N, Fujiwara KT, Kawai S. 1989. v-maf, a viral oncogene that encodes a 'leucine zipper' motif. Proc Natl Acad Sci 86: 7711-7715.

O'Hara AJ, Chugh P, Wang L, Netto EM, Luz E, Harrington WI, Dezube BJ, Damania B, Dittmer DP. 2009. Pre-micro RNA signatures delineate stages of endothelial cell transformation in Kaposi sarcoma. PLoS Pathog 5: e1000389. doi: 10.1371/ journal.ppat.1000389.

Petrova TV, Makinen T, Makela TP, Saarela J, Virtanen I, Ferrell RE, Finegold DN, Kerjaschki D, Yla-Herttuala S, Alitalo K. 2002. Lymphatic endothelial reprogramming of vascular endothelial cells by the Prox-1 homeobox transcription factor. $E M B O$ J 21: 4593-4599.

Pfeffer S, Sewer A, Lagos-Quintana M, Sheridan R, Sander C, Grasser FA, van Dyk LF, Ho CK, Shuman S, Chien M, et al. 2005. Identification of microRNAs of the herpesvirus family. Nat Methods 2: 269-276.

Regezi JA, MacPhail LA, Daniels TE, DeSouza YG, Greenspan JS, Greenspan D. 1993. Human immunodeficiency virus-associated oral Kaposi's sarcoma. A heterogeneous cell population dominated by spindle-shaped endothelial cells. Am J Pathol 143: 240-249.

Ring BZ, Cordes SP, Overbeek PA, Barsh GS. 2000. Regulation of mouse lens fiber cell development and differentiation by the Maf gene. Development 127: 307-317.

Ritchie ME, Silver J, Oshlack A, Holmes M, Diyagama D, Holloway A, Smyth GK. 2007. A comparison of background correction methods for two-colour microarrays. Bioinformatics 23: 2700-2707.

Rodriguez A, Vigorito E, Clare S, Warren MV, Couttet P, Soond DR, van Dongen S, Grocock RJ, Das PP, Miska EA, et al. 2007. Requirement of bic/microRNA-155 for normal immune function. Science 316: 608-611.

Samols MA, Hu J, Skalsky RL, Renne R. 2005. Cloning and identification of a microRNA cluster within the latencyassociated region of Kaposi's sarcoma-associated herpesvirus. J Virol 79: 9301-9305.

Samols MA, Skalsky RL, Maldonado AM, Riva A, Lopez MC, Baker HV, Renne R. 2007. Identification of cellular genes targeted by KSHV-encoded microRNAs. PLoS Pathog 3: e65. doi: 10.1371/journal.ppat.0030065.

Skalsky RL, Samols MA, Plaisance KB, Boss IW, Riva A, Lopez MC, Baker HV, Renne R. 2007. Kaposi's sarcoma-associated herpesvirus encodes an ortholog of miR-155. I Virol 81: 12836-12845.

Smyth GK. 2004. Linear models and empirical bayes methods for assessing differential expression in microarray experiments. Stat Appl Genet Mol Biol 3: Article3. doi: 10.2202/1544-6115. 1027. http://www.bepress.com/sagmb/vol3/iss1/art3.

Staskus KA, Zhong W, Gebhard K, Herndier B, Wang H, Renne R, Beneke J, Pudney J, Anderson DJ, Ganem D, et al. 1997. Kaposi's sarcoma-associated herpesvirus gene expression in endothelial (spindle) tumor cells. J Virol 71: 715-719.

Subramanian A, Tamayo P, Mootha VK, Mukherjee S, Ebert BL, Gillette MA, Paulovich A, Pomeroy SL, Golub TR, Lander ES, et al. 2005. Gene set enrichment analysis: A knowledgebased approach for interpreting genome-wide expression profiles. Proc Natl Acad Sci 102: 15545-15550.

Thum T, Galuppo P, Wolf C, Fiedler J, Kneitz S, van Laake LW, Doevendans PA, Mummery CL, Borlak J, Haverich A, et al. 2007. MicroRNAs in the human heart: A clue to fetal gene reprogramming in heart failure. Circulation 116: 258-267.

Umbach JL, Cullen BR. 2009. The role of RNAi and microRNAs in animal virus replication and antiviral immunity. Genes \& Dev 23: 1151-1164.

Vart RJ, Nikitenko LL, Lagos D, Trotter MW, Cannon M, Bourboulia D, Gratrix F, Takeuchi Y, Boshoff C. 2007. Kaposi's sarcoma-associated herpesvirus-encoded interleukin-6 and G-protein-coupled receptor regulate angiopoietin-2 expression in lymphatic endothelial cells. Cancer Res 67: 4042-4051.

Viswanathan SR, Daley GQ, Gregory RI. 2008. Selective blockade of microRNA processing by Lin28. Science 320: 97-100.

Wang HW, Trotter MW, Lagos D, Bourboulia D, Henderson S, Makinen T, Elliman S, Flanagan AM, Alitalo K, Boshoff C. 2004. Kaposi sarcoma herpesvirus-induced cellular reprogramming contributes to the lymphatic endothelial gene expression in Kaposi sarcoma. Nat Genet 36: 687-693.

Weninger W, Partanen TA, Breiteneder-Geleff S, Mayer C, Kowalski H, Mildner M, Pammer J, Sturzl M, Kerjaschki D, Alitalo K, et al. 1999. Expression of vascular endothelial growth factor receptor-3 and podoplanin suggests a lymphatic endothelial cell origin of Kaposi's sarcoma tumor cells. $L a b$ Invest 79: 243-251.

Wigle JT, Oliver G. 1999. Prox1 function is required for the development of the murine lymphatic system. Cell 98: 769778.

Wigle JT, Harvey N, Detmar M, Lagutina I, Grosveld G, Gunn MD, Jackson DG, Oliver G. 2002. An essential role for Prox1 in the induction of the lymphatic endothelial cell phenotype. EMBO I 21: 1505-1513.

Ziegelbauer JM, Sullivan CS, Ganem D. 2009. Tandem arraybased expression screens identify host mRNA targets of virus-encoded microRNAs. Nat Genet 41: 130-134. 


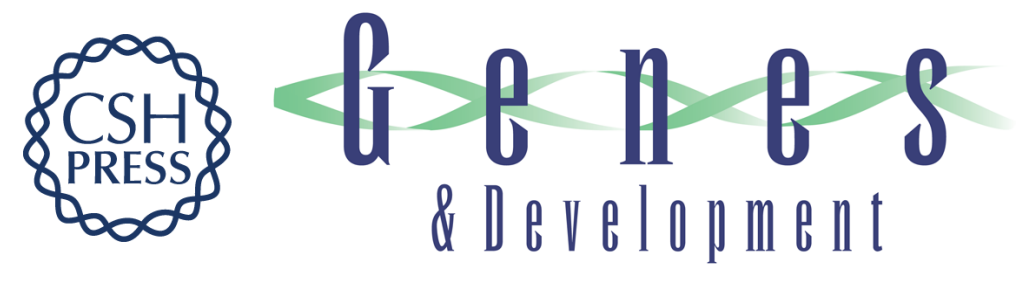

\section{KSHV-encoded miRNAs target MAF to induce endothelial cell reprogramming}

Amy Hansen, Stephen Henderson, Dimitrios Lagos, et al.

Genes Dev. 2010, 24:

Access the most recent version at doi:10.1101/gad.553410

\section{Supplemental http://genesdev.cshlp.org/content/suppl/2009/12/30/24.2.195.DC1 Material}

Related Content

References

This article cites 55 articles, 28 of which can be accessed free at: http://genesdev.cshlp.org/content/24/2/195.full.html\#ref-list-1

Articles cited in:

http://genesdev.cshlp.org/content/24/2/195.full.html\#related-urls

\section{License}

Email Alerting

Service
Changing the Program

John F. Foley

Sci. Signal. January , 2010 3: ec28

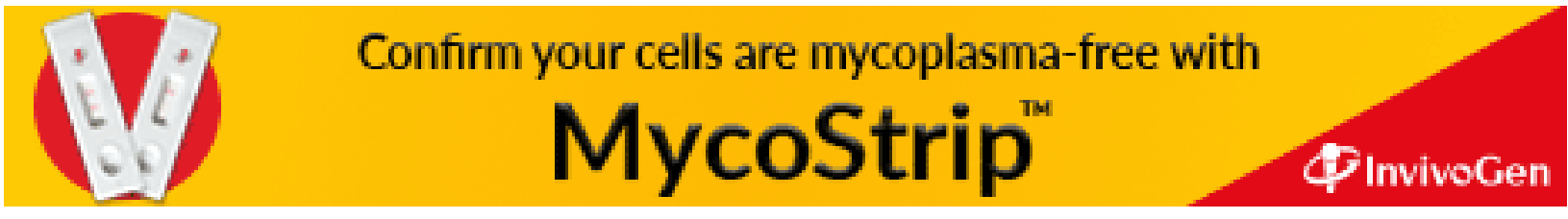

